\title{
\%ounal of Biomedicine
}

2016; 1: 32-35. doi: 10.7150/jbm.16927

Mini-review

\section{Neoadjuvant Chemotherapy Followed by Radiotherapy for Laryngeal Cancer}

\author{
Ilias Karapantzos ${ }^{1}$, Chrysa Karapantzou1 ${ }^{1}$ Paul Zarogoulidis ${ }^{2} \bowtie$, Michail Karanikas ${ }^{3}$, Vasilis Thomaidis ${ }^{4}$, \\ Charalampos Charalampidis ${ }^{5}$ \\ 1. Ear, Nose and Throat Department, "Saint Luke" Private Hospital, Panorama, Thessaloniki, Greece; \\ 2. Pulmonary Department-Oncology Unit, “G. Papanikolaou” General Hospital, Aristotle University of Thessaloniki, Thessaloniki, Greece; \\ 3. General Surgery Department, "Genisis" Private Clinic, Thessaloniki, Greece; \\ 4. Department of Maxillofacial Surgery, University General Hospital of Alexandroupolis, Alexandroupolis, Greece; \\ 5. Department of Anatomy, Democritus University of Thrace, Alexandroupolis, Greece.
}

$\triangle$ Corresponding author: Paul Zarogoulidis, M.D, Ph. D. Pulmonary Department-Oncology Unit, “G. Papanikolaou” General Hospital, Aristotle University of Thessaloniki, Thessaloniki, Greece. Fax: 00302310992424 Mobile: 00306977271974 E-mail: pzarog@hotmail.com.

(c) Ivyspring International Publisher. This is an open access article distributed under the terms of the Creative Commons Attribution (CC BY-NC) license (https://creativecommons.org/licenses/by-nc/4.0/). See http://ivyspring.com/terms for full terms and conditions.

Received: 2016.08.10; Accepted: 2016.09.18; Published: 2016.10.01

\begin{abstract}
Early stage of diagnosis is crucial for laryngeal cancer since the organ and function preservation is wanted from the treating physicians. Currently the optimal care of patients with laryngeal cancer is truly multidisciplinary, with progressive advances in surgical, radiation, and medical oncology. Moreover; molecular targeted therapies are on their way.

Take home message: The treatment of patients with laryngeal cancer with systemic therapy represents an opportunity to positively impact functional outcomes with an anatomically and functionally preserved larynx. Future challenges include identification of novel molecular pathways that upregulate tumorigenesis and suppression of these.
\end{abstract}

Key words: laryngeal cancer, chemotherapy, radiotherapy, molecular therapy.

Neoadjuvant chemotherapy administration prior to definitive irradiation or surgical procedure it has been observed that provides a number of advantages such as the possible eradication of systemic micro metastasis. Moreover; prior to surgery or irradiation chemotherapy is delivered to a tumor which the vessel architecture is unaltered therefore treatment is better delivered. It has been also observed that response to neoadjuvant chemotherapy treatment may also predict the response to subsequent radiation therapy (Figure 1). Neoadjuvant chemotherapy in laryngeal cancer has revolutionized the treatment of this malignant. In the study by Tarpley et al. (1), preoperative methotrexate was firstly administered. Neoadjuvant treatment was further explored in several subsequent clinical trials.(2-9) The largest of these, the Head and Neck Contracts Program, showed that patients with resectable stage III or IV cancer of the oral cavity, larynx and hypopharynx achieved a pathologic CR just only one cycle of preoperative cisplatin and bleomycin chemotherapy. However, it was observed that neoadjuvant chemotherapy failed to demonstrate a benefit in terms of overall survival.(3) Furthermore; Cisplatin and 5-fluorouracil $(\mathrm{PF})$ regimens demonstrated high response rates in patients with previously untreated disease. It has been observed that 30 to $50 \%$ of patients achieved clinical complete responses, with pathologic complete response confirmed in approximately two-thirds of the complete responders.(10) 


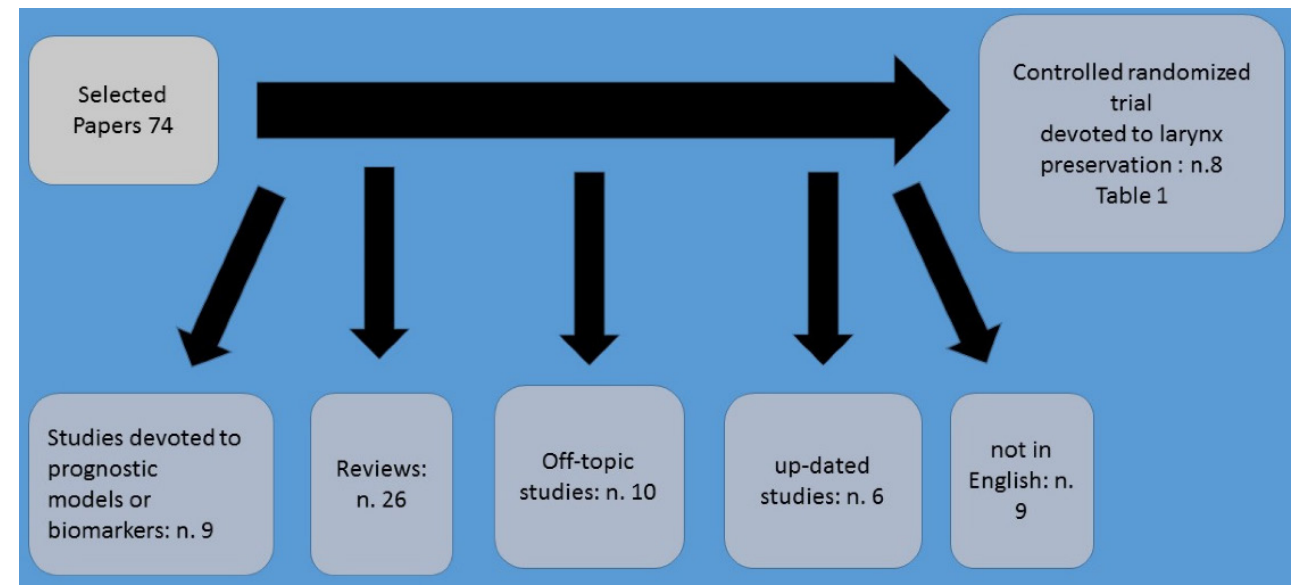

Figure 1. Method of selection.

A significant survival advantage was demonstrated among patients who achieved complete clinical and pathological response following platinum and fluoruracil chemotherapy.(7,11-13) In the study by Jacobs et al. (14) and Karp et al. (15) were the first to incorporate this preoperative chemotherapy treatment as a means to select patients for non-surgical definitive treatment. Based on these findings, the first randomized study of organ-preservation therapy for laryngeal cancer was conducted by the Department of Veterans Affairs (VA) Laryngeal Cancer Study Group.(16) Based on this study which started in 1985, a total of 332 patients with either stage III or stage IV laryngeal cancer (57\% with laryngeal fixation, and $63 \%$ supraglottic tumors) were randomly assigned to one of two treatment strategies. A total laryngectomy followed by radiation and afterwards standard treatment vs chemotherapy followed by either radiotherapy in responding patients or surgery in non-responders. In experimental arm three cycles of induction chemotherapy were included consisting of intravenous cisplatin at $100 \mathrm{mg} / \mathrm{m} 2$ on day 1 and 5 -fluorouracil at $1000 \mathrm{mg} / \mathrm{m} 2 /$ day over $24 \mathrm{~h}$ for five consecutive days.

In order to identify in the best manner, the results three clinical response assessments were performed; A) the first after two cycles of induction chemotherapy administration. If there was not at least a 50\% reduction observed in primary tumor size and at least stable disease in the neck, chemotherapy was stopped and surgery was performed. Afterwards postoperative radiotherapy followed. B) If at least a partial response (> 50\% shrinkage) was observed after two cycles of chemotherapy administration, patients received a third cycle of induction chemotherapy followed by a second tumor assessment and primary site biopsy. Afterwards definitive radiotherapy (66 -76 Gy) followed. C) Finally, after twelve weeks radiotherapy completion, a third tumor assessment by direct laryngoscopy was performed. If the biopsy performed revealed local disease residual disease, then a salvage laryngectomy was performed. If no residual disease was observed, then the patient entered a standardized follow-up schedule. There was a 5-year survival for the two arms of the study and larynx preservation was noted in nearly two-thirds of surviving patients randomized to the induction chemotherapy arm. Also, reduced distant metastasis, were observed, although this observation was not statistically significant. In the publication of the study there was no comparison of the functional quality of life issues between the two arms. However; The study's analysis in 1998 presented data for swallowing and voice functions. Regarding the voice preservation findings observed in the larynx preservation group were better, while the incidence of swallowing abnormalities were even up to 2 years after treatment in the two treatment arms.(17) At that point, non-surgical therapy became a standard of care for the treatment of locally advanced laryngeal cancer.

The second most important randomized induction therapy trial for larynx preservation was conducted by EORTC (the European Organisation for Research and Treatment of Cancer).(18) In this study a total of 194 patients were randomized to standard total laryngectomy and partial pharyngectomy followed by radiotherapy or to induction platinum and fluoruracil chemotherapy followed by radiotherapy in complete responders. It was observed that the rate of complete clinical response to induction chemotherapy was 54\%. Moreover; survival was similar between the study arms, and the functional larynx preservation rate was $48 \%$ at 3 years. A third 
randomized study involving 68 patients by the GETTEC group with T3 laryngeal cancer patients also supported the concept of larynx preservation.(19) In this study, patients had larynx fixation, but only $31 \%$ had a supraglottic tumor. Two-year survival rate was significantly higher in the surgery group than in the chemotherapy group ( 84 vs $69 \%$ ). However; 15 of 36 patients $(42 \%)$ in the chemotherapy group avoided a total laryngectomy. The MACH-NC meta-analysis in these three studies $(n=602)$ found no significant difference in survival, with larynx preservation in $58 \%$ of the surviving patients at 5 years. (20)

In the study by Pointreau et al. (21) a comparison was performed between the effect of three cycles of induction platinum fluoracil with induction docetaxel/cisplatin/fluorouracil in a larynxpreservation study of 213 laryngeal and hypopharyngeal cancer patients. These patients would otherwise require total laryngectomy. The docetaxel/cisplatin/fluorouracil induction regimen consisted of three planned cycles of intravenous docetaxel at $75 \mathrm{mg} / \mathrm{m} 2$ on day 1 , cisplatin at 75 $\mathrm{mg} / \mathrm{m} 2$ on day 1 , and 5-fluorouracil at 750 $\mathrm{mg} / \mathrm{m} 2 /$ day as a 24-h continuous infusion for 5 days, with each cycle administered at intervals of 21 days. Afterwards, patients which responded to induction chemotherapy received radiotherapy (70 Gy to the tumor volume) with or without additional chemotherapy and non-responders underwent total laryngectomy. Radiotherapy followed with or without additional chemotherapy. It was observed that at 3 years, the laryngeal preservation rate in the taxane (docetaxel) group was significantly higher (70.3 vs $57.5 \%, \mathrm{p}=0.03$ ) and the response rate was higher in the taxane group ( 80 vs $59.2 \%, p=0.002$ ), however; there was no difference in overall survival. Table 1. $(16,18,19,21-24)$

Table 1. Most Important studies up-to-date.

\begin{tabular}{lll}
\hline Author (year) & N. pts Site & Stage \\
\hline VALCSG & 332 Laryn & Stage III-IV \\
EORTC 24891 & 202 Hypo pharynx & Stage II-IV \\
GETTEC & 68 Larynx & Stage II-IV \\
GORTEC 2000-01 & 213 Larynx & Stage III and IV \\
EORTC 24954-22950 & 450 Larynx Hypo pharyn & Stage III and? \\
Posner & 166 Larynx & Stage III and IV \\
TREMPLIN & 153 Larynx & Stage III-IV \\
Prades & 71 Pyriform sinus cancer & Stage III-IV \\
\hline
\end{tabular}

\section{Competing Interests}

None to declare.

\section{References}

1. Tarpley JL, Chretien PB, Alexander JC, Jr., Hoye RC, Block JB, Ketcham AS. High dose methotrexate as a preoperative adjuvant in the treatment of epidermoid carcinoma of the head and neck. A feasibility study and clinical trial. American journal of surgery. 1975;130(4):481-6.

2. Kun LE, Toohill RJ, Holoye PY, Duncavage JA, Byhardt RW, Ritch PS, et al. A randomized study of adjuvant chemotherapy for cancer of the upper aerodigestive tract. International journal of radiation oncology, biology, physics. 1986;12(2):173-8.

3. Adjuvant chemotherapy for advanced head and neck squamous carcinoma. Final report of the Head and Neck Contracts Program. Cancer. 1987;60(3):301-11.

4. Toohill RJ, Duncavage JA, Grossmam TW, Malin TC, Teplin RW, Wilson $\mathrm{JF}$, et al. The effects of delay in standard treatment due to induction chemotherapy in two randomized prospective studies. The Laryngoscope. 1987;97(4):407-12.

5. Schuller DE, Metch B, Stein DW, Mattox D, McCracken JD. Preoperative chemotherapy in advanced resectable head and neck cancer: final report of the Southwest Oncology Group. The Laryngoscope. 1988;98(11):1205-11.

6. Gehanno P, Depondt J, Peynegre R, Peytral C, Martin M, Baillet F, et al. Neoadjuvant combination of carboplatin and 5-FU in head and neck cancer: a randomized study. Annals of oncology : official journal of the European Society for Medical Oncology / ESMO. 1992;3 Suppl 3:43-6.

7. Jaulerry C, Rodriguez J, Brunin F, Jouve M, Mosseri V, Point D, et al. Induction chemotherapy in advanced head and neck tumors: results of two randomized trials. International journal of radiation oncology, biology, physics. 1992;23(3):483-9.

8. Mazeron JJ, Martin M, Brun B, Grimard L, Lelievre G, Vergnes L, et al. Induction chemotherapy in head and neck cancer: results of a phase III trial. Head \& neck. 1992;14(2):85-91.

9. Paccagnella A, Orlando A, Marchiori C, Zorat PL, Cavaniglia G, Sileni VC, et al. Phase III trial of initial chemotherapy in stage III or IV head and neck cancers: a study by the Gruppo di Studio sui Tumori della Testa e del Collo. Journal of the National Cancer Institute. 1994;86(4):265-72.

10. Al-Sarraf M. Chemotherapeutic management of head and neck cancer. Cancer metastasis reviews. 1987;6(3):181-98.

11. Ensley JF, Jacobs JR, Weaver A, Kinzie J, Crissman J, Kish JA, et al. Correlation between response to cisplatinum-combination chemotherapy and subsequent radiotherapy in previously untreated patients with advanced squamous cell cancers of the head and neck. Cancer. 1984;54(5):811-4.

12. Glick JH, Marcial V, Richter M, Velez-Garcia E. The adjuvant treatment of inoperable stage III and IV epidermoid carcinoma of the head and neck with platinum and bleomycin infusions prior to definitive radiotherapy: an RTOG pilot study. Cancer. 1980;46(9):1919-24.

13. Hong WK, Bromer RH, Amato DA, Shapshay S, Vincent M, Vaughan C, et al. Patterns of relapse in locally advanced head and neck cancer patients who achieved complete remission after combined modality therapy. Cancer. 1985;56(6):1242-5.

14. Jacobs C, Goffinet DR, Goffinet L, Kohler M, Fee WE. Chemotherapy as a substitute for surgery in the treatment advanced resectable head and neck cancer. A report from the Northern California Oncology Group. Cancer. 1987;60(6):1178-83.

15. Karp DD, Vaughan CW, Carter R, Willett B, Heeren T, Calarese P, et al. Larynx preservation using induction chemotherapy plus radiation therapy as an alternative to laryngectomy in advanced head and neck cancer. A long-term follow-up report. American journal of clinical oncology. 1991;14(4):273-9.

16. Induction chemotherapy plus radiation compared with surgery plus radiation in patients with advanced laryngeal cancer. The Department of Veterans Affairs Laryngeal Cancer Study Group. The New England journal of medicine. 1991;324(24):1685-90.

17. Hillman RE, Walsh MJ, Wolf GT, Fisher SG, Hong WK. Functional outcomes following treatment for advanced laryngeal cancer. Part I--Voice preservation in advanced laryngeal cancer. Part II--Laryngectomy rehabilitation: the state of the art in the VA System. Research Speech-Language Pathologists. Department of Veterans Affairs Laryngeal Cancer Study Group. The Annals of otology, rhinology \& laryngology Supplement. 1998;172:1-27.

18. Lefebvre JL, Chevalier D, Luboinski B, Kirkpatrick A, Collette L, Sahmoud T. Larynx preservation in pyriform sinus cancer: preliminary results of a European Organization for Research and Treatment of Cancer phase III trial. EORTC Head and Neck Cancer Cooperative Group. Journal of the National Cancer Institute. 1996;88(13):890-9. 
19. Richard JM, Sancho-Garnier H, Pessey JJ, Luboinski B, Lefebvre JL, Dehesdin D, et al. Randomized trial of induction chemotherapy in larynx carcinoma. Oral oncology. 1998;34(3):224-8.

20. Pignon JP, Bourhis J, Domenge C, Designe L. Chemotherapy added to locoregional treatment for head and neck squamous-cell carcinoma: three meta-analyses of updated individual data. MACH-NC Collaborative Group. Meta-Analysis of Chemotherapy on Head and Neck Cancer. Lancet. 2000;355(9208):949-55.

21. Pointreau Y, Garaud P, Chapet S, Sire C, Tuchais C, Tortochaux J, et al. Randomized trial of induction chemotherapy with cisplatin and 5-fluorouracil with or without docetaxel for larynx preservation. Journal of the National Cancer Institute. 2009;101(7):498-506.

22. Lefebvre JL, Rolland F, Tesselaar M, Bardet E, Leemans CR, Geoffrois L, et al. Phase 3 randomized trial on larynx preservation comparing sequential vs alternating chemotherapy and radiotherapy. Journal of the National Cancer Institute. 2009;101(3):142-52.

23. Prades JM, Lallemant B, Garrel R, Reyt E, Righini C, Schmitt T, et al. Randomized phase III trial comparing induction chemotherapy followed by radiotherapy to concomitant chemoradiotherapy for laryngeal preservation in T3M0 pyriform sinus carcinoma. Acta oto-laryngologica. 2010;130(1):150-5.

24. Lefebvre JL, Pointreau Y, Rolland F, Alfonsi M, Baudoux A, Sire C, et al. Induction chemotherapy followed by either chemoradiotherapy or bioradiotherapy for larynx preservation: the TREMPLIN randomized phase II study. Journal of clinical oncology: official journal of the American Society of Clinical Oncology. 2013;31(7):853-9. 